\title{
Orchard Grass Pollen IgG4 Measurement
}

National Cancer Institute

\section{Source}

National Cancer Institute. Orchard Grass Pollen Ig G4 Measurement. NCI Thesaurus.

Code C130083.

A measurement of the orchard grass (Dactylis glomerata) pollen IgG4 in a biological specimen. 